\title{
Develar y apreciar la diversidad organizacional: discursos y prácticas para re- imaginar la empresa y la estrategia en función de la vida *
}

\author{
Reveal and appreciate organizational diversity: speeches and practices for re-imagining enterprise and strategy on \\ favor of the life
}

Desvelar e valorizar a diversidade organizacional: discursos e práticas para re-imaginar a empresa e as estratégias em função da vida

\author{
Juan Manuel Arévalo Viveros ${ }^{\mathrm{a}}$ \\ Universidad del Cauca, Colombia \\ juanarevalo@unicauca.edu.co \\ ORCID: http://orcid.org/0000-0001-5760-9157 \\ Franklyn Mosquera Pisso \\ Universidad del Cauca, Colombia \\ ORCID: http://orcid.org/0000-0002-2806-0043 \\ Diego Cáceres Barajas \\ Universidad del Cauca, Colombia \\ ORCID: http://orcid.org/0000-0002-9043-8131
}

Fecha de recepción: 27/09/2018

DOI: https://doi.org/10.11144/Javeriana.cao32-58.dado Redalyc: http://www.redalyc.org/articulo.oa?id=20560207005

\section{Resumen:}

El presente artículo aborda algunos de los discursos y prácticas con el potencial necesario para la emergencia transicional de horizontes estratégicos post-desarrollistas en el medio empresarial de Popayán. Partiendo de la relación empresa-desarrollo, se pretende hacer aportes a la estrategia empresarial-organizacional teniendo como horizontes el postdesarrollo y el contra-desarrollo vital (configuración de estadios sociales para la sustentabilidad de la vida y la diversidad socio-natural). Concluimos que la emergencia de horizontes estratégicos post-desarrollistas se debate entre las propuestas empresariales y los planteamientos de las organizaciones sociales. Sin embargo, en estas últimas hay mayor potencial para resignificar las estrategias. En este estudio privilegiamos metodologías cualitativas/constructivistas/interpretativas, y métodos de investigación documental, entrevistas y observación etnográfica.

Códigos JEL: M14, Q01

Palabras clave: empresa, estrategia, posdesarrollo, contra-desarrollo vital, Popayán.

\section{Abstract:}

This paper addresses some of the discourses and practices with adequate capacity to allow the emergency of post-developmental strategic horizons, in the Popayan business environment. Starting from the relationship between enterprise and development, we aim to offer resources to enterprise-organizational strategy, taking in count insights of pos-developmental and vital contradevelopmental processes (construction of social contexts around of sustainability of life, and social and natural diversity). We found that the transitional emergency of pos-developmental strategic horizons might be built between proposals of enterprises and social organizations. However, the last ones have more potential for re-meaning the strategies. This study privileges a qualitative, constructivist and interpretative methodology, and methods of documentary research and ethnographic interviews and observations.

JEL Codes: M14, Q01

Keywords: Enterprise, strategy, posdevelopment, vital contra-development, Popayán.

\section{Resumo:}

O presente artigo aborda alguns dos discursos e práticas com o suficiente potencial para a emergência transicional de horizontes estratégicos pós-desenvolvimentistas no meio empresarial de Popayán. Partindo da relação empresa-desenvolvimento, pretende-se

Notas de autor:

\footnotetext{
a Autor de correspondencia. Correo electrónico: juanarevalo@unicauca.edu.co
} 
fazer aportes à estratégia organizacional-empresarial, tendo como horizontes o pós-desenvolvimento e o contra-desenvolvimento vital (configuração de estágios sociais para a sustentabilidade da vida e a diversidade sócio-natural). Concluímos que a emergência de horizontes estratégicos pós-desenvolvimentistas se debate entre as propostas empresariais e as demandas das organizações sociais. Entretanto, estas últimas têm maior potencial para re-significar as estratégias. Neste estudo privilegiamos metodologias qualitativas/construtivistas/interpretativas e os métodos de pesquisa documental, entrevistas e observação etnográfica.

Códigos JEL: M14, Q01

Palavras-chave: empresa, estratégia, pós-desenvolvimento, contra-desenvolvimento vital, Popayán.

\section{Introducción}

En el mundo moderno es cada vez más evidente la relación empresa - desarrollo, la cual se concreta mediante las renovadas dinámicas del Estado neoliberal. No obstante, la empresa materializa un desarrollo en función del capital y no de los contextos socio-naturales (Arévalo, 2013). Considerando lo anterior, el manuscrito tiene como propósito presentar algunos avances alrededor del tema del re-diseño de la estrategia de las empresas a fin de que aquellas sean consonantes con un contra-desarrollo vital funcional a la vida. ${ }^{[1]} \mathrm{El}$ interrogante para desarrollar el tema es ¿En los momentos actuales, cuáles son algunos de los discursos y prácticas que se desarrollan en Popayán - Cauca con el potencial necesario para imaginar la emergencia transicional de horizontes estratégicos posdesarrollistas? La postura defendida destaca que la emergencia transicional de horizontes estratégicos posdesarrollistas se debate entre las propuestas convencionales de las empresas y el Estado y las apuestas de las organizaciones en cuyo centro de gravedad está la vida más que el capital. ${ }^{[2]}$ Por supuesto, resulta evidente que es desde estos últimos agenciamientos donde se encuentra un mayor potencial para la re-significación del panorama estratégico y de las empresas en favor de la existencia humana y no humana (contra-desarrollo vital). Concretamente, primero se teorizará sobre la cuestión de la emergencia transicional de los horizontes estratégicos posdesarrollistas, seguidamente se presentarán consideraciones de orden contextual, luego algunas de las propuestas de las organizaciones empresariales y finalmente se indicarán las apuestas de las organizaciones de otro modo que giran en torno a la defensa de la vida.

El trabajo privilegia una metodología cualitativa constructivista e interpretativa. El método fue el estudio de casos cualitativo, temporal, múltiple y holístico. En cada caso se consideraron las mismas variables e instrumentos, no obstante, se realizaron ajustes según las particularidades. Las técnicas de producción de datos utilizadas fueron la investigación documental, las entrevistas y la observación etnográfica; ello permitió la "triangulación" de resultados para incrementar su validez. El tratamiento de datos se desarrolló mediante un proceso de análisis-síntesis, intertextualidad y construcción de textos argumentativos. El universo de estudio se situó en Popayán, Cauca y fue múltiple toda vez que en el proceso participaron empresas de capital privadas, organizaciones sociales, investigadores y actores sociales clave. Los criterios teóricos para la selección de los casos empresariales fueron: existencia de planificación estratégica formal, organizaciones poco investigadas, desarrollo de operaciones e incidencias en Popayán y la existencia de vínculos importantes en dichas instituciones que facilitaran el acceso. Para la selección de las organizaciones sociales, los investigadores y los actores sociales clave, se utilizó principalmente la técnica de bola de nieve. Por motivos de confidencialidad se usaron convenciones y no nombres propios, de manera que los colaboradores son identificados con los números I1 a I25. 


\section{Imaginando la emergencia transicional de horizontes estratégicos posdesarrollistas: consideraciones teóricas}

En el marco del hegemónico, heterogéneo y disputado sistema/mundo/moderno/capitalista (Grosso, 2012), la empresa y el desarrollo son fenómenos fundamentales que mantienen relaciones interdependientes concretadas por el Estado neoliberal (Ahumada, 1996; Moncayo, 2012). No obstante, es cierto que la institución empresarial termina por materializar un desarrollo funcional al capital en detrimento de muchas de las condiciones que garantizan la vida. Por tal razón, se vislumbra la necesidad de adelantar estudios inter/ trans disciplinarios que permitan, por una parte, problematizar la actual responsabilidad a cargo de la empresa, y por otra parte, generar nuevos conocimientos y prácticas de cara a re-configurar lo empresarial en función de nuestra era y contextos, esto es, en dirección al logro de un contra-desarrollo vital (Arévalo, 2013). ${ }^{[3]}$

En tal dirección, una contribución importante emerge al desafiar los discursos/prácticas convencionales/ funcionalistas que se promueven sobre estrategia organizacional. Al respecto, obsérvese que la disciplina científico/moderna de la administración es un campo del conocimiento que permite la coordinación eficiente de la institución empresarial. Luego, si aquella deviene y mantiene la lógica de la modernidad y por ende del sistema del capital en sus fundamentos de base (Camisón \& Dalmau, 2009; Mintzberg, 2001; Braudel, 1997), se infiere que la coordinación que impulsa implica en mayor medida una armonización de las empresas hacia el objetivo prevaleciente de la acumulación incesante de capital. Entre otras razones, es por ello que estas organizaciones terminan por conceptualizar/instaurar en los contextos sociales un desarrollo modernizador. Ahora bien, la estrategia ${ }^{[4]}$ es uno de los ejes clave de la administración para proporcionar tal coordinación funcionalista a las instituciones empresariales. ${ }^{[5]}$ Así, desafiar las representaciones convencionales de tal acepción podría constituirse en un punto vital para re-significar la institución empresarial de cara a la promoción de un contra-desarrollo vital en los contextos sociales.

Es necesario re pensar los discursos/prácticas de la estrategia a partir de otras alternativas posibles y disidentes con respecto a la lógica homogeneizadora del capital, desde otras epistemologías, tal y como lo plantea el posdesarrollo. Claro está, es este acto re-configurador lo que proponemos como emergencia de horizontes estratégicos posdesarrollistas en el presente trabajo.

El posdesarrollo emerge desde 1991 como un conjunto de discursos y prácticas que abogan por la creación de diferentes discursos y representaciones no tan mediadas desde la óptica del desarrollo occidental, intentando así cambiar las prácticas de saber y hacer. Promueve por ende la visibilización de centros y agentes de producción de conocimientos que han sido invisibilizados, tanto en el norte como en el sur global, a fin de construir un mundo más humano basado en nociones de sostenibilidad, buen vivir, autonomía, diversidad/ pluralidad y economías y culturas alternativas. De igual forma, el posdesarrollo implica la descolonización de los imaginarios y la deseconomización de los espíritus, se trata de poner en el centro de la vida humana otras significaciones y razones de ser diferentes a la expansión de la producción y el consumo, pensando global y localmente al mismo tiempo, así como considerando al decrecimiento y las alternativas locales concretas como perspectivas significativas (Latouche, 2003; Carvajal, 2009; Escobar, 2005; Sachs, 1996; Gudynas, 2011).

Ahora bien, repensar la estrategia organizacional desde el posdesarrollo o gestar los horizontes estratégicos posdesarrollistas implicaría aprender y generar estrategias cimentándose en otras ontologías y epistemologías bajo las cuales se tenga otra forma de ver, saber y hacer en el mundo, diferente a las lógicas del sistema y bajo las cuales todo ser viviente y sus formas de vida deben superar el lugar prioritario actual del capital. En esta dirección, Quijano (2012) destaca que en América Latina existe un horizonte económico plural, en el que coexisten culturas que entienden y hacen economías de otros modos en forma paralela a las economías liberales capitalistas. Estas formas económicas emergentes distan de la lógica del capital, priorizan más bien la reproducción ampliada de la vida, producen sociedad y se dirigen hacia una mejor satisfacción de las necesidades legítimas para sus comunidades. Así mismo, existen diversas iniciativas que se anclan al 
biocentrismo. Ahora bien, lo anterior implica que en nuestros contextos sociales existe multiplicidad de tipos y formas de organización, muchas de ellas dirigidas hacia el contra-desarrollo vital.

De esta forma, si lo pretendido es aprender de otras ontologías/epistemologías que prioricen la vida para ensanchar las analíticas sobre la estrategia y si se pretende emprender procesos de aprendizaje/búsqueda de estrategias articuladas a las realidades contextuales, resulta pertinente considerar, analizar y aprender de la pluralidad y diversidad de estrategias que siguen estas iniciativas organizacionales. ${ }^{[6]}$ Por lo anterior, según Grosso (2012) se necesita una ciencia social crítica en América Latina que promueva un conocimiento ampliado que visibilice formas de conocer otras silenciadas y constitutivas de nuestros conocimientos, filosofía, historia y lenguaje. Esto permitiría ensanchar las analíticas, reconocer otras verdades e introducir innovaciones y transformaciones importantes.

Cabe destacar que lo planteado sobre los horizontes estratégicos posdesarrollistas, está en coherencia con las propuestas sobre transiciones civilizatorias de múltiples movimientos sociales que giran en torno a la (re) comunalización, las heterotopías en favor de la vida, la especificidad socio-cultural, el territorio, los saberes, las ontologías (cosmovisiones) y otros mundos posibles, expresiones que se presentan como asuntos locales pero constituyendo redes en las dinámicas globalocales (Quijano, 2015). Las transiciones suponen exceder los límites institucionales y epistémicos a fin de visualizar otros mundos y prácticas con potencial para impulsar las transformaciones significativas y necesarias para un mundo atravesado por diversas crisis ecológicas y sociales. Dadas estas coherencias discursivas, podría hablarse entonces de una emergencia transicional de horizontes estratégicos posdesarrollistas.

Así, se podría concluir que los aprendizajes y avances que supondría la emergencia transicional de horizontes estratégicos posdesarrollistas, podrían contribuir a una transformación de lo empresarial en dirección a la concreción de un contra-desarrollo vital en los contextos sociales. ${ }^{[7]}$ Por supuesto, materializar tal entronque no es simple, toda vez que, aprender/pensar/desplegar la estrategia desde el posdesarrollo supondría pensar/actuar [desde el] poscapitalismo y [la] posmodernidad (transmodernidad en el sentido de Dussel). Al respecto, retomando y adaptando aportes de Gibson-Graham (2011), ello implicaría, 1. Una ética del pensamiento: autocultivarnos como sujetos capaces de imaginar y practicar nuevas economías, organizaciones y estrategias. Se trata de un proceso de escoger-cambiar el ser, el pensamiento y el mundo/la acción; 2. Una política del lenguaje: dislocar el dominio discursivo/práctico de la economía única y universal a partir del lenguaje económico diverso y descolonizado que entregue posibilidades para sustentar nuevas economías, organizaciones y estrategias; 3 . Una política del sujeto: liberarnos del tipo de sujeto creado por la economía y constituir sujetos que deseen y creen el no capitalismo. Esto implica una resubjetivación coherente a una economía diferente y comunitaria, que dé paso al sujeto que gestiona las organizaciones y sus estrategias desde otros imaginarios en procura de la vida; y 4. Una política de la acción colectiva: crear conciencias y esfuerzos colectivos combinados, agrupaciones de proyectos e iniciativas que permitan la construcción de una nueva realidad económica, organizacional y estratégica.

\section{Popayán - Cauca (Colombia): un contexto pluriversal alentador de la diversidad organizacional y las apuestas en favor de la emergencia transicional de los horizontes estratégicos posdesarrollistas}

En el presente acápite se presenta una sintética línea argumental sobre el porqué en la ciudad de Popayán han proliferado organizaciones con propuestas concretas entorno a la emergencia transicional de los horizontes estratégicos posdesarrollistas. Resulta necesario discutir algunas consideraciones sobre la cuestión, por cuanto se debe reconocer que todo tipo de organización y sus propuestas se enmarcan y subyacen desde procesos históricos - políticos - económicos - culturales de realidades contextuales específicas. 
Como tesis central se plantea que el contexto de Popayán refleja claramente lo denominado por Escobar $(2016,2017)$ y Dussel $(2015)$ como una realidad pluriversal, es decir, recordando a los zapatistas mexicanos, un mundo en donde caben muchos mundos. Más específicamente, se debe anotar que en estos territorios del suroccidente colombiano, proliferan de forma subordinada y disputada pero con vasta resistencia frente a las instituciones de la modernidad, variedad de mundos que practican un "más allá" de la vida moderna generadora de crisis socio-ecológicas, mundos que constantemente buscan transicionar hacia la reinvención de lo humano, la convivialidad y el re-tejer lo socio-natural, preocupándose principalmente por el sufrimiento humano y el destino de la vida. En Popayán convergen conflictiva y complementariamente multiplicidad de ontologías, algunas de las cuales se configuran a partir de lógicas duales, colonizadoras y defensoras de la acumulación incesante de capital; empero, al mismo tiempo, perviven proyectos ontológicos de otros modos, relacionales - no dualistas, que giran en torno a la defensa y reconstrucción del pluriverso, el territorio, la ancestralidad, la autonomía, la articulación profunda de todos los procesos socio-naturales, y en suma, la sustentabilidad radical de la vida humana - no humana.

Para desarrollar la tesis anteriormente esbozada, en primera instancia se debe anotar que la ciudad de Popayán es la capital del Departamento del Cauca, se ubica en el suroccidente de Colombia entre las cordilleras occidental y central sobre el valle de Pubenza. Geográfica y demográficamente, el municipio cuenta con un área urbana total de 2.725 hectáreas, un suelo de expansión de 292,63 hectáreas y un suelo rural que representa el 95\% del área total del municipio que es de 51.200 hectáreas. ${ }^{[8]}$ Su altitud media es de 1760 metros sobre el nivel del mar y limita al oriente con los municipios de Totoró, Puracé y el Departamento del Huila; al occidente con los municipios de El Tambo y Timbío; al norte con Cajibío y Totoró y al sur con los municipios de Sotará y Puracé. Así mismo, se puede resaltar que para el año 2010 la ciudad contaba con una población total de 267.976 habitantes, de los cuales 238.499 pertenecen a la cabecera municipal y 29.477 a la zona rural (Alcaldía de Popayán, 2012). La Ciudad Blanca como se conoce, es una de las más antiguas y mejor conservadas de América, ello se refleja en la arquitectura colonial y las tradiciones religiosas de gran atractivo en el país.

De acuerdo con Zuluaga (2007), la historia de Popayán se remonta a la época prehispánica en la cual su contexto social se caracterizaba por ser una región húmeda y boscosa en la que habitaban grupos indígenas. Según Castrillón (2007), tales grupos estaban organizados por líderes y contaban con gran desarrollo cultural. Al llegar los españoles se generaron luchas colonizadoras mediante las cuales los europeos buscaron siempre imponer su cultura, economía, política, religión, idioma, escritura y experiencias bélicas. Los extranjeros expulsaron a los indígenas de sus posiciones para tomarlas y luego buscar territorios planos aptos para su subsistencia. Producto de ello, se funda la otrora villa de Ampudia, luego villa de Popayán (13 de enero de 1537) y desde el 6 de junio de 1538 la ciudad de Popayán, proceso liderado por Sebastián de Belalcázar.

Luego de su fundación, este territorio se convirtió en un punto muy importante en el Virreinato de la Nueva Granada, se construyeron importantes edificaciones coloniales y templos religiosos, instituciones que permitieron asegurar el control de los habitantes (Pérez, 2014). Los indios, y posteriormente negros africanos, fueron tomados para realizar trabajos forzosos en una zona que inicialmente fue generadora de gran riqueza minera y agrícola (Zuluaga, 2007). En definitiva, entre los siglos XVI y XVIII se produce en Popayán la concreción de un proceso colonial que configura una nueva composición social, cultural y ambiental, produciéndose una fuerte ruptura de los procesos ancestrales adaptativos, relacionales y sustentables propios de los pueblos originarios.

No obstante, cabe resaltar que desde los inicios de la colonización hasta nuestros días, las resistencias en la región no se hicieron esperar, las diversas formas de esclavitud y dominación (el reparto, la encomienda o la mita, el terraje, etc.) no tuvieron buena acogida entre las poblaciones locales. La insubordinación estaba servida. Se producen así luchas como la de la Gaitana (Wey Tana o abuela en lengua nasa) que reunió más de 12.000 guerreros entre los pueblos yancones, pijaos, piramas, guanacas y nasas en defensa de los indígenas, Juan Tama alrededor de los pueblos Nasa, las negociaciones subversivas de los Misak y las resistencias de 
cimarrones en las haciendas esclavistas, procesos que han servido de base para las pugnas en los siglos XIX y XX de personajes y organizaciones como Manuel Quitín Lame (sus herederos y “nietos”) quien emprendió batallas en pro del no pago de terraje y para hacer valer los títulos coloniales que habían sido entregados a los indígenas del Cauca, Alfonso Peña Chepe (comunero Nasa) y Lorenzo Muelas (indígena Misak) representantes indígenas en la Asamblea Nacional Constituyente que promovió la constitución política colombiana de 1991, la Asociación Nacional de Usuarios Campesinos -ANUC-que aglutinó sectores de campesinos pobres, indígenas y comunidades negras, el Consejo Regional Indígena del Cauca-CRIC- que influyó sobre las luchas indígenas y de diferentes movimientos sociales del país, entre muchos otros procesos más. En efecto, a pesar de que muchos indígenas y negros se adaptaron a la forma de vida de los españoles, hibridando sus tradiciones, cosmologías y dinámicas sociales (surgiendo de ello los mestizajes), otros se protegieron en las montañas y zonas marginales, conformaron resguardos y palenques, construyeron sistemas de interacción con la naturaleza y lucharon contra los españoles, ello a fin de obtener los sustentos, evitar los desplazamientos y defender su libertad, logrando como resultado a lo largo de la historia de la región, una serie de reformas en beneficio de los sectores marginados (Zuluaga, 2007; De Roux, 1991; Quijano, Corredor, \& Tobar, 2014; Cúneo \& Gascó, 2013).

Durante las guerras de independencia y los primeros días de la vida republicana de Colombia en el siglo XIX, Popayán constituyó un lugar central para el resguardo de tropas, convirtiéndose en un foco de luchas políticas que poco a poco permitieron la entrega del poder a los terratenientes criollos. Esto comportó la necesidad de cambios de organización social de los pobladores, debiendo dejar de lado muchas costumbres heredadas de los españoles. Sin embargo, esta situación también generó despoblamiento, pobreza y desigualdad. Popayán, al igual que la nación, sufría un desgaste económico, político, social y moral, además la iglesia católica seguía siendo una institución que mantenía sumergido al pueblo en la ignorancia y la obediencia. Luego de la guerra de los mil días (1899-1903), la estabilidad del país se tornará promisoria, inicia el ingreso de la modernidad a los diferentes contextos del territorio nacional, incluido Popayán, y así, ciencia, arte, movimientos intelectuales y conceptos de democracia y justicia comienzan a reflejarse en las clases dirigentes (Zuluaga, 2007). Empero, por aquellos tiempos del transcurrir del siglo XX, debido a la pérdida del poder económico y político del Cauca como consecuencia de las nuevas formas de organización nacional, Popayán y la región empiezan a atravesar un periodo de estancamiento, luchas por el control de tierras, algunos pocos avances en infraestructura y tecnología, ricos empobrecidos, espacios políticos exclusión donde se negó la participación de sectores marginados y las consiguientes emergencias aceleradas de procesos organizativos de resistencia que debían enfrentar las respuestas cada vez más violentas de los terratenientes (Quijano, Corredor \& Tobar, 2014; Cúneo \& Gascó, 2013).

De esta manera, los procesos de los siglos XIX y XX, pasando por un fuerte terremoto en el año de 1983 que derivó grandes implicaciones, desembocaron en una recomposición de las resistencias ${ }^{[9]}$, críticas a los sistemas de servidumbres asociados al terraje y las consecuentes luchas indígenas por la recuperación de la tierra, reconocimiento de la diversidad étnica, cultural y ambiental, migraciones poblacionales tanto de la región como de otros departamentos, el incremento de zonas periféricas y nuevos procesos de re-configuración política-económica-cultural (Zuluaga, 2007; Quijano, Corredor, \& Tobar, 2014; Macuacé \& Cortés, 2013).

Ya con el advenimiento de nuevos conflictos sociales y el modelo neoliberal de finales del siglo XX e inicios del siglo XXI, Popayán y la región asisten a la instalación de la libre empresa, la apertura económica y la mercantilización social y de la naturaleza, todo lo cual afecta las actividades y condiciones de vida de las poblaciones vulnerables y marginadas. Sin embargo, frente a estas nuevas realidades, la trayectoria organizativa de la región ha proporcionado propuestas, proyectos y espacios para la defensa de la vida y de lo comunal, ello a pesar de constantes nuevos auges de violencia en su contra. Al respecto, Cúneo y Gascó, recordando la voz de Álviro Calambas, plantearon “En 2010, el gigante minero Anglo Gold Ashanti comenzó a trabajar sin permiso de las comunidades [...]. Fuimos y decomisamos la retroexcavadora. Ahora la tenemos aquí y sirve para hacer trabajo comunitario" (Cúneo \& Gascó, 2013, p. 225). 
Considerando estas realidades históricas, Hernández y Díaz (2003) plantean que Popayán, tan solo con su centro histórico y su "blancura" no alcanza a agrupar toda esa diversidad que hoy la constituye. Por supuesto, se trata de una multiplicidad entre la que se destaca la fuerte presencia, incidencia y luchas ontológicoterritoriales por parte de comunidades y organizaciones indígenas, afrodescendientes, campesinas, urbanomarginales, entre otras. Ello a pesar de los continuados procesos de exterminio y marginación en su contra, ya no a manos de los españoles, sino por parte de élites locales/nacionales, que a pesar de los procesos de "independencia y descolonización" del siglo XIX, siguieron en defensa de un mundo moderno/capitalista muy propio de la herencia euro-norteamericana, destruyendo a su paso todo proyecto ontológico distinto o extraño que resultase amenazador. Es de anotar que muchas de las comunidades resistentes en mención, precisamente al tener que defender su pervivencia afrontando condiciones de exclusión histórica, a partir de sus raíces y apegos ancentrales-territoriales, han tenido que mantener-(re)diseñar concepciones y prácticas de vida comunitarias, relacionales y sustentables bastante opuestas a las instauradas por los mundos modernos/ capitalistas.

Según lo anteriormente planteado, se evidencia que Popayán, e incluso la región a la que pertenece, es decir todo el departamento del Cauca y el suroccidente colombiano en donde se viven condiciones semejantes de pluriversidad histórica, se constituyen como espacios-tiempos tanto de centenaria historia de resistencia (frente a conquistadores, terratenientes, Estados, Transnacionales y grupos armados) como de diversidad socio-natural y múltiples procesos histórico-culturales-políticos-económicos, ello a pesar de su engranaje al sistema mundo moderno capitalista (Quijano, Corredor \& Tobar, 2014; Cúneo \& Gascó, 2013). Claro está, estas trayectorias de larga duración han auspiciado procesos sociales y formas de relacionamiento, de apropiación y significación en distintas direcciones. Así entonces, las pugnas y resistencias frente al mundo del capital por parte de distintas comunidades, grupos y organizaciones, siguen tan vigentes hoy como en el siglo XVI en defesa de los territorios, la educación y pensamiento propio, la naturaleza, las espiritualidades, la autonomía y las condiciones dignas de pervivencia de humanos y no humanos. Lo anterior a partir de "procesos, estrategias y proyectos sociales de diferente tipo, en los que se usa la escritura, la ley, la referencia conceptual del mundo del colonizador a la vez que se reza, se embruja, se canta y se baila desde imaginarios propios" (Quijano, Corredor \& Tobar, 2014, p. 223). En este orden ideas, se puede concluir que Popayán y la región del Cauca se constituyen en

\footnotetext{
"escenarios complejos, litigiosos e igualmente esperanzadores, con diferentes manifestaciones de agentividad social y de experimentación creativa en favor de la vida. ... El espacio-tiempo del Cauca, [incluido Popayán], es una multiplicidad de mundos, una diversidad de formas de ser y estar que no acaban únicamente en las cifras y estadísticas oficiales que lo señalan como lugar de pobreza, desesperanza y fracaso. Los territorios del Cauca son lugares de construcción y resignificación organizativa donde se movilizan apuestas de reencantamiento a través de formas de experimentación y en horizontes de esperanza y posibilidad, mundos de pluriversidad que se construyen desde las prácticas intelectuales de indígenas, negros, campesinos, mujeres y jóvenes, quienes no son siempre puntos de referencia para académicos, planificadores del desarrollo, agentes de cooperación o para la tecnocracia estatal, pues, contrariamente, para muchos de estos agentes constituyen óbices al desarrollo. (Quijano, Corredor \& Tobar, 2014, pp. 222, 224)”
}

Por supuesto, las características contextuales de Popayán descritas se reflejan latentemente en el campo económico - organizacional. De esta forma, se vivencia en la región, por una parte, la expansión de un tejido empresarial con visos capitalistas. Obsérvese que, a pesar de que la ciudad ha sido representada más como tierra de poetas, intelectuales y políticos, que se erigen como "los muertos que viven todavía" (Sánchez, 1967, p. 7), en donde no cobran importancia los empresarios del contexto y su vocación, cuyas actividades han sido siempre muy frágiles (Crist, 1950), desde la década de 1960, este sector empresarial progresivamente se proyecta como un tejido diverso que se despliega y se formaliza. Es así como según cifras de la Cámara de Comercio del Cauca, Popayán para el año 2018 alberga ya 12.526 unidades empresariales. Así mismo, desde inicios del siglo XX, esta ciudad viene siendo anfitriona de corporaciones transnacionales, entre las cuales, según estudios propios adelantados con Pabón y Rogríguez (2018) y Becerra y Puentes (2017), se han 
identificado inicialmente 17 unidades girando alrededor de los sectores de alimentos, energético, financiero, industrial, petrolero, retail, telecomunicaciones, transporte aéreo y de mercancías.

\begin{tabular}{lcc}
\hline & Tamaño & Número total \\
\hline Micro & & 11.993 \\
Pequeña & & 440 \\
Mediana & & 78 \\
Grande & & 15 \\
& Total & 12.526
\end{tabular}

FIGURA 1

Empresas matriculadas y renovadas en la ciudad de Popayán, 2018

Fuente: elaboración propia.

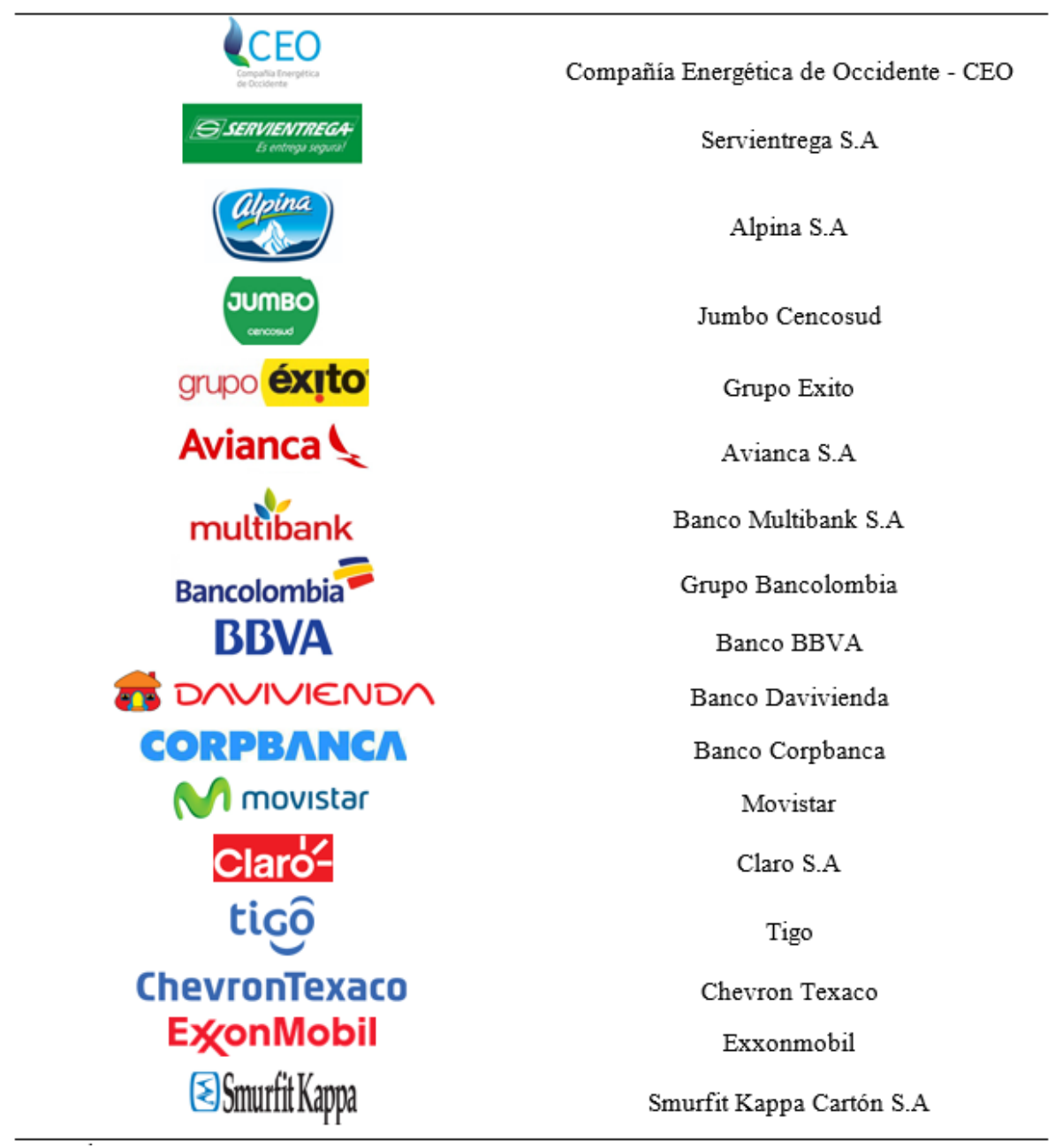

FIGURA 2

Listado de empresas transnacionales que operan actualmente en Popayán Fuente: elaboración propia.

Paralelamente, en Popayán y el Cauca, proliferan organizaciones y procesos comunitarios de otros modos, que al estar en disidencia a la lógica del mundo moderno, no necesariamente coinciden con los intereses de la acumulación incesante de capital, sino más bien, en muchas ocasiones, con la defensa y garantía de la vida ampliada (humana y no humana). Nos referimos aquí a la diversidad de organismos sociales y procesos 
indígenas, campesinos, afrodescendientes y otros múltiples tipos de organizaciones sociales que tienen lugar en el contexto.

\begin{tabular}{lrr}
\hline \multicolumn{1}{c}{ Organización jurídica } & Activas & $\begin{array}{c}\text { Participación } \\
\text { (\%) }\end{array}$ \\
\hline Asociaciones agropecuarias y campesinas nacionales y no nacionales & 435 & $7 \%$ \\
\hline Asociaciones mutuales & 40 & $1 \%$ \\
\hline Corporaciones & 178 & $3 \%$ \\
\hline Entidades de naturaleza cooperativa & 355 & $6 \%$ \\
\hline Fondo de empleados & 50 & $1 \%$ \\
\hline Fundaciones & 29 & $0 \%$ \\
\hline Instituciones auxiliares del cooperativismo & 9 & $0 \%$ \\
\hline Las demás organizaciones civiles, corporaciones, fundaciones & 4977 & $82 \%$ \\
\hline
\end{tabular}

FIGURA 3

Organizaciones sociales en el departamento del Cauca

Fuente: Mera (2015).

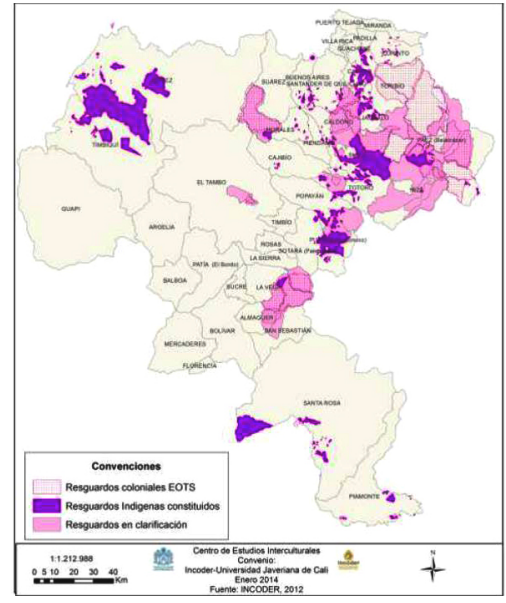

FIGURA 4.

Procesos territoriales indígenas en el departamento del Cauca Fuente: Duarte (2013).

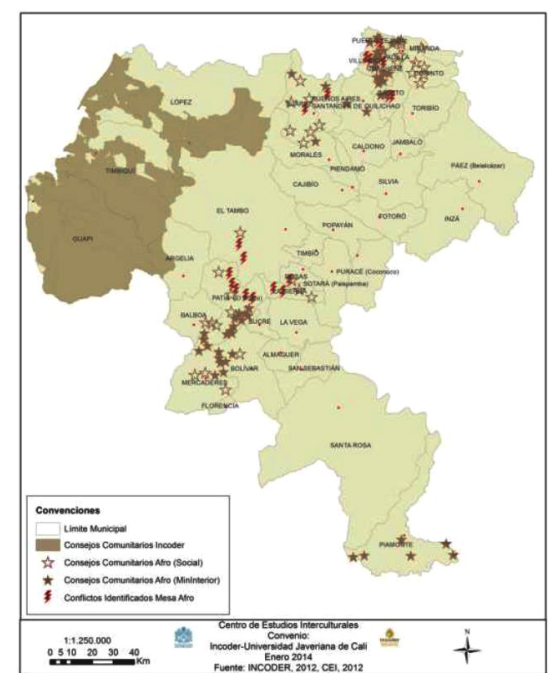

FIGURA 5.

Procesos territoriales Afro en el departamento del Cauca

Fuente: Duarte (2013). 


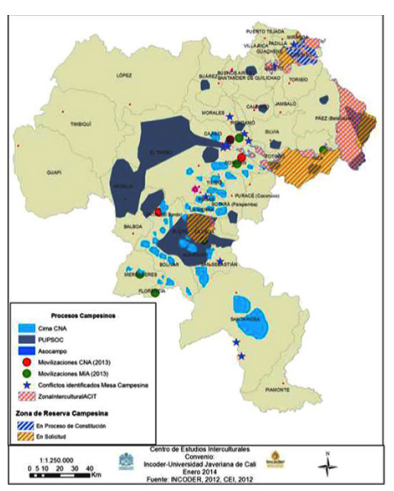

FIGURA 6.

Procesos campesinos en el departamento del Cauca

Fuente: Duarte (2013)

Finalmente, los argumentos presentados nos permiten concluir que es apenas comprensible que en el marco de un contexto históricamente pluriversal como el de la ciudad de Popayán, se hayan erigido y se encuentren presentes tanto configuraciones organizacionales como comunidades que plantean y practican propuestas concretas, plausibles y convincentes entorno a lo definido en el acápite anterior como la emergencia transicional de los horizontes estratégicos posdesarrollistas.

\section{Propuestas para la emergencia transicional de horizontes estratégicos posdesarrollistas}

\section{Propuestas de las organizaciones empresariales}

Según los aportes de los colaboradores (I2), (I3), (I5), (I6), (I7), (I8), (I9), (I10), (I11), (I12), (I14), (I16) y (I17), los planteamientos de las organizaciones empresariales giran alrededor de las siguientes cuestiones:

1. Pensar en las utilidades sin desconocer las necesidades de la comunidad; 2. Fomentar la formación y educación; 3. Construir infraestructuras para incrementar la producción, el empleo y el mejoramiento de las condiciones de trabajo (esto último es secundario y ha sido incumplido); 4. Establecer vínculos entre la empresa, sus fundaciones, otras empresas y el Estado para gestar proyectos de desarrollo para la comunidad y el ambiente en los contextos en los que se opera y para diseñar mejores ambientes de trabajo para las empresas; 5. Implementar estrategias de motivación y bienestar de los empleados a través de paseos, actividades lúdicas, celebraciones para los hijos y fiestas de integración; 6. Diversificar, satisfacer al cliente y generar mejoras continuas que generen rentabilidad para obtener los ingresos y así impactos sociales; 7 . Preocuparse por el ser humano y sus necesidades lo cual requerirá de una dirección humana; 8 . Promover la autogestión, microempresa familiar y asociatividad en las comunidades (transferencia de la lógica del capital en detrimento de la diversidad cultural y económica); 9. Dignificar y humanizar el trabajo, es decir tecnificarlo para incrementar su comodidad y eficiencia (generación de desempleo); 10. Optimizar el uso de combustibles, invertir en infraestructura y generar conocimientos; 11 . Mejorar la calidad; 12. Erradicar la accidentalidad de trabajadores; y 13. Practicar la responsabilidad social empresarial.

Por supuesto, hay actores (I13 e I15) que arguyen que las empresas solo reafirman el discurso y la actuación del capital, apuntaladas por un Estado ineficiente e incapaz. Solo cuidan su imagen para el logro de legitimidad social y para ocultar sus prácticas de acumulación incesante de capital.

Según lo anterior, las organizaciones empresariales plantean propuestas opcionales para la emergencia transicional de horizontes estratégicos posdesarrollistas. Empero, tales apuestas pierden su potencial re- 
significador al anclarse aún en la lógica del desarrollo modernizador, el capital y la competitividad. Así, es menester buscar alternativas estratégicas más coherentes con el contra-desarrollo vital. Aquellas podrían encontrarse más fácilmente en las organizaciones sociales con potencial posdesarrollista.

\section{Sobre las organizaciones sociales con potencial posdesarrollista}

Ensamblando conceptos de Johansen (1992), Sisto (s.f.), Rifkin (1998), Handy (1996), Lee \& Hassard (1999), Boucher (1999), Morrison \& Milliken (2000), Maturana \& Varela (1987), Latouche (2003), Carvajal (2009), Escobar (2005) y considerando las conversaciones sostenidas con los actores (I18), (I19), (I22), (I23), (I24) e (I25), planteamos que las organizaciones sociales con potencial posdesarrollista, como otros tipos de organización, son aquellos sistemas sociales complejos en no equilibrio, compuestos por individuos y cosas materiales e inmateriales que configuran subsistemas (formales, sociales e informales) que, tanto en su interior como en sus interrelaciones con otros subsistemas, despliegan un comportamiento marcado por la heterogeneidad y la complejidad. Además, a nivel holístico, mantienen un comportamiento relativamente abierto. Estos organismos sociales se presentan fenoménicamente como entes dinámicos, flexibles, con límites difusos y en donde se maximiza la interacción, operando por tanto, en una realidad intersubjetiva abierta, compleja y fragmentada que ofrece inestabilidad más que la estabilidad propia de la burocracia moderna. En suma, se trata de organizaciones que despliegan comportamientos autopoiéticos con acoplamiento estructural ${ }^{[10]}$. Sin embargo, a diferencia de otro tipo de organizaciones, las sociales con potencial posdesarrollista son aquellas que:

- A pesar de sus heterogeneidades, conflictividades y contrariedades y sin ser el lugar total de la pureza, lo higiénico, moral y positivo, tienden a una conducta que gira en torno a la comunalidad y la reciprocidad, por ende alrededor del cuidado, la compasión, la colectividad y la cooperación. En consecuencia, su lógica de operación no transcurre prioritariamente a través de la acumulación incesante de capital ${ }^{[11]}$, sino más bien alrededor de la producción y reproducción ampliada de la vida digna de seres humanos y no humanos - biológicos y no biológicos que coexisten de manera relacional $^{[12]}$ en los contextos sociales.

- Sus operaciones abogan por la calidad de vida (un buen vivir) y el respeto de la diversidad económica, cultural y natural. Igualmente, los mecanismos de coordinación tratan de transcurrir por medio de planificaciones y decisiones democráticas y participativas.

- Tienden a desarrollar posturas biocéntricas y relacionales frente a la naturaleza (no antropocéntrico); y frente a los sujetos, no tanto relaciones sujeto-objeto (proxémica), sino relacionamientos sujetosujeto (horizontalidad y proximidad). Además, no tratan el dinero como una mercancía para generar más dinero, sino como un medio de intercambio para facilitar la circulación de otras mercancías que satisfacen necesidades legítimas.

- Luchan por el derecho a la naturaleza y el buen vivir, considerando que de la cosecha no solo comen los humanos sino también otros seres biológicos y no biológicos. Por ende, no buscan producir más con menos, sino menos para más (aminoramiento de las utilidades para la maximización de la vida). En la misma dirección, consideran que los miembros son parte más no dueños de la tierra, por tanto, es su obligación la defensa de aquella considerada siempre como sujeto.

- Defienden los cambios autónomos (no heterónomos) y trascienden la lógica productivista, toda vez que, lo económico les es trascendente en tanto significa la vida digna en sí misma, pero trabajan también por temas de derechos humanos y culturales, reivindicaciones de mujeres y jóvenes, planes de vida, derechos propios, (re)significación y apropiación efectiva y afectiva de los territorios, producción limpia, energías alternativas, educaciones propias-alternativas, modelos de salud pertinentes y gobiernos con relaciones efectivas de poder no jerárquicas y que operen bajo el 
mandar obedeciendo. También trabajan por las tiendas comunitarias, la recuperación de tierras, de la historia y del protagonismo de la gente de las bases, por la construcción de procesos sociales, la recuperación de la identidad, construcción de economías solidarias propias, soberanía alimentaria y defensa de la vida.

En suma y dejando por fuera otras características, las organizaciones sociales con potencial posdesarrollista son aquellas que al cuestionar los asuntos del desarrollo hegemónico, trabajan desde los intentos de la gente común, desde la marginalidad, 'los invisibles' o 'condenados de la tierra' (niños, mujeres, jóvenes, y productores en general) que interpelan al sistema para superar su situación de exclusión y construir mundos más humanos, cultural y ecológicamente sostenibles. Son organizaciones que crean/piensan (a nivel global-local) y se cimentan en discursos distintos ${ }^{[13]}$ a los del mundo moderno-occidental. Por ello, generan conceptualizaciones y prácticas alternas, basadas en nociones de sostenibilidad, autonomía, diversidad y economías alternativas y disidentes. Es de resaltar que, estos organismos se configuran de varias maneras según los contextos, empero siempre buscan diversos modos de expansión colectiva en los que no se privilegia un bienestar material destructor del medio ambiente y el lazo social.

Finalmente, a partir de los estudios de Duarte (2013) y Mera (2015), se elaboró un listado con ejemplos significativos del amplio y variopinto panorama de organizaciones sociales del departamento del Cauca. (ver el Anexo).

\section{Aportes de las organizaciones sociales para la emergencia transicional de horizontes estratégicos posdesarrollistas}

Antes de plantear las propuestas sobre los horizontes estratégicos posdesarrollistas, en primera medida observemos que tales estrategias se enmarcan en sistemas administrativos caracterizados tangencialmente así:

Acorde con el colaborador (I18), tales sistemas giran en torno a la autogestión y la solidaridad. Lo primero refiere no tanto a la administración convencional de recursos, sino más bien al cuidado de la vida ampliada (seres biológicos y hasta no biológicos) como objetivo prioritario. En suma, la autogestión da cuenta de la relación administración - cuidado, se administra individual y colectivamente para dar vida. Por su parte, la solidaridad refiere al establecimiento de vínculos con las alteridades próximas, la construcción de mundos y tejidos comunes que giran en torno a lo económico y a lo social. Adicionalmente, se resalta que en estos sistemas se intenta superar la idea convencional del trabajo para otorgarle una concepción múltiple atravesada por una cosmovisión más social que económica.

Por otra parte, el actor (I19) devela que la vocería, las asambleas y la rotación del poder son puntales relevantes de los sistemas administrativos. Las vocerías son la materialización del precepto "mandar obedeciendo". Nadie toma decisiones por su cuenta, no hay líderes que hablan por los grupos, lo que hay es voceros que aglutinan iniciativas y las ponen en común al interior y con otras organizaciones. El vocero es así un espacio de comunicación que permite canalizar y socializar iniciativas, necesidades, propuestas y experiencias. Por otra parte, los dirigentes solo pueden tener máximo dos años de gobierno, esto es la rotación del poder que permite que la gente entienda cuál es la lógica de ser gobernador. Así entonces, el poder está en todos y es rotatorio, no es estable, se promueve por tanto la democracia. Las asambleas son los espacios de reflexión más importantes para tomar decisiones comunales. Son esferas complejas y que pueden convertirse en encuentros continuados de meses o años para tomar decisiones certeras y eficaces en su implementación.

Para el participante (I22) los sistemas administrativos en cuestión poseen complejas redes de autoridad en distintas apuestas organizativas que se ligan por instituciones que coordinan y mediante diversos y heterogéneos planes de vida. Empero, contrariamente a la administración convencional, no se pretende uniformizar tales apuestas, sino ubicar puntos comunes y mantener y promover la diversidad. Llama la atención que en estas formas otras de gestión no es impensable establecer relaciones económicas por fuera 
del mercado convencional, así, el trueque familiar y solidario, sin necesidad de dinero ni de equiparación de precios, transcurre efectivamente para el intercambio y para suplir las necesidades legítimas. De igual forma, se promueve la idea de la no explotación y el aprovechamiento sostenido y equilibrado de los recursos.

El participante (I24) arguye que los sistemas administrativos en mención transcurren mediante un proceso ampliamente participativo constituido por talleres de formación y de intercambio, asambleas adaptadas a distintos intereses, coordinadores y diferentes personas, mujeres y jóvenes, que dinamizan la organización desde distintas necesidades. Adicionalmente, el actor (I23) destaca que estos sistemas administrativos son dinámicos, no estáticos.

El colaborador (I25) expresa que lo más interesante en este tipo de administración son los principios, como por ejemplo, el principio de la abstención de la acumulación, según el cual siempre hay un control social que garantiza que ninguna persona tenga más que otra. Las mismas organizaciones asignan responsabilidades de carácter redistributivo a quienes hayan logrado acumular más. Así mismo, son importantes los principios con los que se observa a la gente. Se entiende que las personas son la matriz vital. Otros aspectos relevantes y novedosos que destaca el colaborador son las formas de agruparse y debatir los problemas colectivos, es decir, la asociatividad; la innovación para la vida; las estructuras diferentes de tenencia de la tierra y la administración del agua; y el presentar como fortaleza la reducción de las utilidades (lo que interesa no es tanto la acumulación per se, sino la extensión ampliada de servicios para beneficio de las personas). En definitiva, se trata de una economía y gestión pensada y gestada en favor de la vida.

A pesar lo anterior, los participantes (I19) e (I21) dejan en claro que no se debe desconocer que los sistemas administrativos de las organizaciones sociales son también un híbrido por cuanto no distan totalmente de la administración convencional. Por supuesto, la lógica administrativa empresarial no es adoptada total y acríticamente. Lo que acaece es un proceso de adopción y adaptación estratégica, en función de las necesidades locales y las formas en cómo se va desenvolviendo la cotidianidad de los organismos sociales. Esto coincide con organizaciones en movimiento que se adecuan fácilmente a diferentes situaciones.

Ahora bien, en el marco de los sistemas administrativos de los organismos postdesarrollistas, emergen propuestas de estrategias organizacionales novedosas y con alto potencial re-configurador de las organizaciones en favor de la vida. Dichas propuestas son aún invisibles bajo las teorías convencionales, por tanto con el ánimo de contribuir a su iluminación, seguidamente se hará una breve descripción del panorama estratégico posdesarrollista que se puede vislumbrar desde algunas organizaciones sociales en Popayán.

A partir de las contribuciones de los colaboradores (I18), (I23) e (I25), se argumenta que dentro de las estrategias que podrían contribuir a la emergencia transicional de horizontes estratégicos posdesarrollistas, se encuentra la asociación, política de acción colectiva o asociatividad, la cual consiste en que todo trabajo realizado deviene de esfuerzos colectivos entre vecinos y parientes, es decir, estrategias de lazos comunes que permiten aprender a ser colectivos en todo el sentido de la palabra. Ello se relaciona con la solidaridad y la autogestión.

“-¿En tal marco, cuáles podrían ser las estrategias que se plantean e implementan?- Vivir armónicamente con tu economía, con las personas que vives, con tus vecinos y tener una economía solidaria que no está basada en la competencia, no tienes que competir con tus vecinos sino ayudar a vivir en cooperación, el poder retribuir, servir y tener la sensación de familia más allá de tu familia de sangre, [se trata de] una red familiar que si te pasa algo ahí está la gente para ayudarte [...], [en suma, se trata de] estrategias de juntarse para hacer cosas en común (Participante I23)."

Hay similitud entre las estrategias de la escuela política de las teorías administrativas convencionales y las estrategias de asociatividad, empero, estas últimas giran en torno a otros valores y lenguajes que conllevan a prácticas distintas. Por ejemplo, las relaciones sociales frías y calculadas entre socios, competidores, proveedores y clientes, son reemplazadas por relaciones comunitarias cercanas y cálidas entre parientes y vecinos.

El colaborador (I25) plantea que otra de las estrategias clave es de orden epistémico: tratar de cambiar la denominación de las cosas a fin de que aquellas puedan devenir en otras. Es la política del lenguaje que 
intenta construir imágenes y léxicos nuevos para una transición civilizatoria. Los nuevos lenguajes intentan transfigurar el mundo por cuanto se encuentran cargados de otras ideologías y nuevas representaciones consonantes con un mundo diferente, más justo, equitativo, diverso y heterogéneo. Por ejemplo, obsérvese la cita de un texto de las comunidades Zapatistas: "A loas compañeroas de la sexta: A loas interesadoas" (EZLN, 2015, p. 21). Se explica posteriormente sobre las palabras citadas que "no [se debe] olvidar la equidad de género y el reconocimiento de la diversidad" (EZLN, 2015, p. 24).

Aparecen en el panorama también otras estrategias tales como la movilización o "movigestión", la interiorización, la determinación de momentos clave y la afectividad. Con respecto a la primera, los colaboradores (I19), (I22) e (I24) argumentan que hace referencia a los patrones de formas mediante los cuales se gestionan proyectos, procesos y derechos consonantes con los planes de vida ante el Estado. No se espera a que llegue la institucionalidad, hay movilización para gestionar y ser escuchados. La movigestión es una estrategia que da cuenta de una verdadera organización compleja, múltiple y en movimiento.

En la misma línea, las estrategias de orden político que menciona el colaborador (I25), que son aquellas utilizadas por las organizaciones para no ser negadas por el sistema. Empero, también se tratan de acciones éticas, educativas y económicas de otros modos y disidentes. Con relación a lo económico, el colaborador (I24) comenta sobre la estrategia de economías propias, que según el colaborador (I12), está constituida por los lazos de reciprocidad.

Por su parte, la estrategia de la tradición oral o interiorización refiere a contar y repetir continuadamente la historia para que la gente interiorice una situación y luego pueda fácilmente recrearla. Mientras que en la administración convencional se plasma y comunica las estrategias mediante un plan estratégico, en las organizaciones posdesarrollistas, los objetivos y estrategias deben ser contados, escuchados y repetidos muchas veces.

"Otra práctica que me parece importante es que resulta fundamental repetir la historia, es decir, en muchos lugares va a ver gente que está contando la historia y a usted ya le va parecer repetitivo esto, es como que éste me está contando la historia que yo ya sé, entonces llega el momento en que a uno le parece la repetidera y la repetidera. Se trata de la estrategia de la tradición oral que permite interiorizar [la historia y las situaciones y] fácilmente recrearlas [...]. Fijate que nosotros creemos que eso se solucionaría escribiendo un libro, para ellos es una cosa que debe ser contada, evaluada, escuchada, y repetida, muchas veces (colaborador I19)."

En coherencia con lo anterior, el actor (I24) enuncia la estrategia de formación de conciencia como la interiorización de lo que se dice para lograr consistencia entre los discursos y las prácticas. Aquello tiene que ver con la generación de confianza, mecanismo que reemplaza el control estratégico tradicional. Así entonces, estrategia y confianza son elementos inseparables.

En lo que refiere a la estrategia de determinación de momentos clave, esta tiene que ver con la comprensión de los momentos políticos vitales para desarrollar las acciones importantes. Con respecto a la afectividad, el colaborador (I19) plantea que es una estrategia relacionada con la construcción de lazos afectivos que son difíciles de romper, trascienden las relaciones contractuales por cuanto se trata más de haber estado y luchado con el otro y compartir ideas colectivas para transformar la organización.

El colaborador (I21) enuncia que otros objetivos/estrategias importantes son la formación en diferentes niveles, la organización, la articulación, la incidencia y la concientización/construcción. Las dos primeras tienen que ver con el mejoramiento de procesos organizativos para buscar mayor participación y una vida más orgánica. La articulación es una estrategia relacionada con la construcción de redes locales, nacionales e internacionales. Esto también es mencionado por los colaboradores (I22), (I23) (I24) e (I25) bajo las denominaciones de estrategias de relación y visibilización o políticas de acción colectiva. La incidencia busca que el Estado asuma y respete los derechos de las comunidades y se hagan cumplir. Por su parte, la concientización/construcción es una estrategia asociada con agrupar y organizar a la gente para construir mancomunadamente propuestas y procesos de transformación. 
El actor (I22) destaca que las estrategias de formación en torno a lo político-organizativo, las cuales permiten que la gente conozca qué es la diversidad, su historia, los planes de vida, el buen vivir, el porqué de la lucha por la tierra y la importancia de lo colectivo. Con la formación técnica, se busca hacer entender el por qué se han logrado las conquistas territoriales, culturales y económicas. Y con la formación administrativa, preparar en cuanto a derecho propio, ley de origen, derecho mayor, manejo de fichas y marcos lógicos.

El colaborador (I24) también enuncia la realización de talleres como estrategia asociada con la creación de encuentros para discutir sobre los derechos, lo que acontece en los territorios, intercambios prácticos de saberes y de bienes y servicios, procesos de formación y la producción y sus insumos. En suma, son los espacios para sensibilizar y reafirmar los procesos sociales que se construyen.

Finalmente, otra estrategia planteada por el actor (I23) es la denomina transición inspiración. Aquella refiere a la creación de espacios (como ecoaldeas) para re-subjetivar a las personas y permitirles volver a reencontrarse con lo real, con el día a día, aprendiendo de propuestas de vida no tan cómodas pero en donde existe una verdadera responsabilidad para con la sociedad y la naturaleza. Son esferas de vida que inspiran al vecino y al que viene de afuera a experimentarlas y reproducirlas. En palabras del colaborador (I25), son políticas del sujeto para construir seres distintos que puedan contraponerse o desear menos el sistema desarrollista - capitalista.

"La transición es muy importante, va ir a ayudando para que la gente vaya despertando sin que sea un balde de agua [y]
empiece a pensar como persona, como familia, como gente del mundo, de humanos, gente de una sociedad [...]. La transición
inspiración de la que hablamos es una estrategia para poder llegar a los objetivos, y no sólo se trata de inspirar a uno, inspiras
al vecino, a los que están aquí, al que viene de afuera, y se hace un cambio global no sólo a nivel de tu vida sino a nivel de
planeta (colaborador I23)."

En cuanto a la formulación de las estrategias, se destaca que se hace principalmente mediante procesos participativos y determinados por principios y valores sumamente sostenibles.

\begin{abstract}
“[Para la formación de sus estrategias, las organizaciones sociales con potencial posdesarrollista] primero hacen que la gente empiece a vincularse y a identificar claramente los problemas que tienen. En seguida, recuerdan claramente sus principios sociales, como lo es la solidaridad, entonces todo problema [es abordado estratégicamente] desde este tipo de principios sociales y culturales. Finalmente realizan una apropiación de otros agentes o actores como el estado y el mercado, que se incorporan aquí para obtener un objetivo no productivista ni utilitarista, sino para contribuir al desarrollo de la vida digna. [En ese sentido, las organizaciones sociales al momento de formular sus estrategias] entran y salen [del mercado y de lo estatal], no lo excluyen, son posibilidades, es parte de lo posible, pero no es el punto de llegada. (Colaborador I18).

[...] - ¿Cómo se llega a concebir las estrategias?- Hacemos asambleas locales con lluvia de ideas, hacemos también reuniones regionales y reuniones de planeación a nivel local, zonal, regional y nacional [...]. [Así entonces la formación de estrategia] es en conjunto [...] mirando que iniciativas se mueven desde el potencial de cada localidad. (Colaborador I24)."
\end{abstract}

Así mismo, los colaboradores (I19) e (I21) nos permiten argumentar que la formación de las estrategias transcurre mediante un proceso político y de aprendizaje,

\footnotetext{
"Casi siempre consideramos estos movimientos como organismos muy compactos y homogéneos y lo que habría que mirar son las presiones al interior de los mismos, tensiones generacionales, de género y políticas. Esta serie de discusiones muchas veces no son resueltas, pero lo importante es que existe algo que [...] los mantiene unidos a pesar de la diferencia, acá pueden haber formas distintas de comprender problemas o fenómenos, pero a pesar de eso, no se disuelve la organización porque hay cosas importantes que los unen y los mantiene cohesionados [...]. Las tensiones terminan resolviendo el qué nos une y el qué nos hace más compactos, sin olvidar las diferencias. (Colaborador I19).

[...] Se reflexiona mucho sobre las prácticas y prácticas sencillas que parecieron irrelevantes pero que tienen sentido, [...] esas prácticas han llevado a madurar y reflexionar la misma organización [...]. La verdad es que son aprendizajes que las organizaciones tienen, y a partir de estos mejoran, [hay cambios] producto de errores pasados y de construcciones que no salieron bien, pero que de alguna manera u otra significan procesos autorreflexivos muy importantes. (Colaborador I21).”
}

Igualmente, los colaboradores (I19) e (I22) reconocen que la formación de estrategia se da en un entorno colectivo-asambleario que demanda tiempo para llegar a consensos de largo plazo. Así, se reconoce que las estrategias emergen de procesos culturales colectivos en donde la gente se reúne, piensa y define. Para tal 
fin, se desarrollan conversatorios, talleres y congresos. En los primeros, se reúnen los mayores que tienen un conocimiento vasto de los procesos sociales. Son espacios libres de grabación, notas y órdenes del día a fin de promover diálogos horizontales y abiertos. Los resultados obtenidos sirven para consejería con respecto a las estrategias. En los talleres se tratan temáticas específicas con metodologías definidas. Los congresos son procesos colectivos de consenso que involucran mayor población y en donde se tratan temáticas extensas con un orden del día riguroso. Surgen de aquí las directrices estratégicas a seguir.

Los colaboradores (I21), (I22) e (I24) reconocen que también existen procesos de planificación formal de largo plazo para la creación de estrategias. Tal es el caso de los planes de vida. Empero, estos procesos son holísticos y desarrollados por todos a partir de lo que visionan para sus comunidades. Es de resaltar que en los planes se piensa y se re-piensan las organizaciones más allá de lo meramente económico, por ende dan cabida a lo cultural, los jóvenes, la esencia de las comunidades, el futuro de las generaciones, el territorio, el agua, lo ambiental, la seguridad alimentaria, entre otros aspectos. Además, los planes de vida no giran en torno a presupuestos, parten de lo que todos pueden hacer y de las actividades para motivar a las personas y erigir comunidad.

El colaborador (I18) afirma que una vez claras las apuestas estratégicas sigue un proceso de recordación para que tales apuestas se arraiguen en la organización. Esto se relaciona con la tradición oral y el retorno al mito que son la fuente de los principios y valores que cimentan las estrategias y el mundo del organismo social. En estas formas de asegurar la implementación de las estrategias, la vigilancia y el control administrativo son secundarios o se anulan y son reemplazados por los principios de confianza y reciprocidad que se dan con la vida misma, se sienten, están inmersos en las acciones.

\footnotetext{
“-¿Cómo la organización logra controlar la implementación de las estrategias?- Nosotros trabajamos es con confianzas, creemos que lo que mandatamos en las reuniones, en las asambleas es lo que vamos a seguir realizando [...]. Como todo es mandatado por todos en la organización, toda la gente controla lo que se hizo y no se hizo, hay fuertes debates. De esta forma, la palabra control puede ser remplazada por confianza, afinidades y debates [...]. [Por ejemplo], si tú vas a un territorio a un evento y te dan la comida en cajas desechables, tú dices ¿̨ónde está la coherencia de lo ambiental? [...], la idea es ser coherentes, [y tal coherencia] se logra mediante la estrategia de formación de conciencia, y así entre más coherentes más confianza [...].¿Y cómo logran ser coherentes?- Es un nivel de conciencia entre lo que decimos con lo que hacemos, hay que interiorizar eso. [Para eso] el proceso de formación, porque que tengamos escrito un mecanismo no, nadie nos obliga [...], hay que tenerlo muy claro para poderlo interiorizar y así empezarlo a implementar. (Colaborador I24)."
}

El colaborador (I19) destaca que "no es que exista un cuadro de control que pudiera permitir el análisis del cómo nos fue aquí", esto se logra en la medida que los procesos van avanzando y madurando y se dan amplios diálogos, ello en reemplazo de las sistematizaciones escritas. Por su parte, el colaborador (I22) argumenta que para lograr coordinación en la implementación de las estrategias, se utiliza la participación horizontal democrática comunitaria, diversa y heterogénea mediante consejerías y asociaciones.

Por otra parte, el colaborador (I21) afirma que en lo relacionado con la estrategia, su formación e implementación en las organizaciones posdesarrollistas, la administración convencional ha aportado. Se deben reconocer dos cosas, primero que esta última tiene enfoque empresarial, pero si se logrará adaptar a la gestión de procesos sociales se podrían lograr resultados; y segundo, desde las comunidades se han realizado también innovaciones importantes sobre procesos estratégicos para re-significar dinámicas en favor de la vida.

Reafirmando lo anterior está el actor (I23) quien arguye que la creación e implementación de estrategias se da con la sociocracia, un proceso de consenso con estructuras verticales y horizontales paralelamente. Así, hay grupos especializados en actividades específicas que tienen potestad de decisión, pero también existe un núcleo superior que articula y toma las grandes decisiones. Tal núcleo tiene representación de todas las células y en aquel se toman decisiones participativas con las propuestas de cada delegado y se construye desde el aprendizaje continuo. Lo importante es que las articulaciones se realizan mediante metodologías como el círculo de la palabra, las cuales se erigen de forma que ninguna palabra vaya en contra de nadie y se privilegie el tejido constructivo y la escucha sin respuestas necesariamente inmediatas. 
Ahora bien, se podría afirmar que los anteriores procesos estratégicos de las organizaciones sociales, parecen tener un gran potencial re-configurador para la emergencia transicional de horizontes estratégicos posdesarrollistas que permitan una mayor coherencia con respecto a la idea del contra-desarrollo vital en los contextos sociales. Obsérvese las manifestaciones de los colaboradores (I18), (I19), (I21), (I22), (I23) e (I24) con respecto a los objetivos y formas de desarrollo que fundamentan y emergen a partir de las estrategias de las organizaciones potencial posdesarrollista.

"Estas organizaciones están buscando vida digna, [...] un bienestar en el mundo, mundos que sean posibles, [...] en mi concepto lo que he visto de los indígenas es que están buscando mundos posibles, [...] la dignidad o el bien estar son deseos en construcción [...]. Entonces hay que entender ese desarrollo en varias aristas, varias dimensiones, [...] es una búsqueda del estar bien en la sociedad, donde se respete la vida, haya respeto por las mujeres, los jóvenes, los niños y sus derechos, la educación, la creatividad, la lúdica, [...] pero también la vida no humana, como decía un taita indígena, a nosotros nos toca hablar por los animales y por la naturaleza. [Estas organizaciones buscan] la defensa del territorio, la defensa de la vida, y todo tiene que ver con lo económico pasando por lo social, lo cultural, lo educativo, los derechos sociales y culturales [...].

[...] Se apuesta a conseguir una economía propia y soberanía alimentaria, recuperación de la semilla, educación a la familia, proceso productivo enfocado en el mercado local, producción de abastecimiento propio, [...] la reconstrucción de la identidad, [...] reivindicación de los derechos, [...] hablamos de bienes comunes como la tierra, el agua, la semilla, el aire, las montañas.

[...] El desarrollo está muy centrado en la reconexión del ser humano con sigo mismo y con la naturaleza, se trata de "la unidad”, que es el darse cuenta que uno hace parte de un territorio global, de una energía general, que todos somos lo mismo, que esa piedra, que ese árbol, es lo mismo pero en configuraciones diferentes. Entonces es más un Biocentrismo que un antropocentrismo, [...] se ayuda a las personas a tener experiencias de reconexión, [...] una espiritualidad ligada a la naturaleza, [...] se da un mestizaje de todo, no es solo cosas indígenas, todo es una unidad, [...] se promueve mucho la pluralidad, el desarrollo de una diversidad en donde no se te dicen que tienes que creer, sino que se te abren puertas [...]. Somos diversos y podemos cada uno en su forma vivir en armonía con la tierra, usted lo hace de esta forma y más bien juntémonos, digamos cómo lo puedo ayudar y usted como me puede ayudar y esta es una forma de entender el mundo [...]. [Por supuesto], en el centro de todo está la vida, la priorización de la vida en su sentido amplio, la piedra, los espíritus de la naturaleza, en suma, la comunidad extendida [...]. La idea es vivir armónicamente con tu economía, con las personas, con tus vecinos y tener una economía solidaria no basada en la competencia, el poder retribuir, el poder servir y tener la sensación de familia, una red familiar que si te pasa algo ahí está la gente para ayudarte, el poder generar a través de esa colectividad menos impacto ambiental y espacios de buen vivir, de reconexión contigo mismo, con tu comunidad, con el ambiente, economías menos agresivas con la familia, es decir que permitan tener más tiempo para estar con aquella."

Finalmente, se debe precisar que con la emergencia transicional de horizontes estratégicos posdesarrollistas no se pretende configurar una administración y una empresa que se olvide de lo económico, sino más bien que se trate a esta esfera como una más de sus procesos y como un medio para la promoción de la vida ampliada humana y no humana, biológica y no biológica. Igualmente, se pretende que la empresa y su administración sean cuestiones más complejas y relacionales que considere las diversas dimensiones que implica la vida ampliada. Al respecto de esto las voces de los actores (I15) e (I25) respectivamente,

\footnotetext{
“[Lo ideal sería] pensar la administración no en función de la acumulación, sino en función de la distribución, entonces podrían surgir otros conocimientos, otras prácticas, que serían totalmente distintas. Cuando el conocimiento se pone a favor de la acumulación, beneficia a unos pocos, pero cuando se lo pone a favor de la distribución beneficia a muchos, porque son muchos los que se van a beneficiarse de la riqueza. Incluso este sería el caso de una administración aplicada a una relación más armónica con la naturaleza [...]. [...] Permitir que todos pudiéramos gozar de agua potable, de energía, que todos los muchachos tuvieran acceso a estudio hasta el nivel de universidad, que la gente tuviera acceso a la tierra para producir, que el trabajo fuera pagado al menos diríamos en base a la ley, que en el desarrollo de procesos productivos pudieran tener garantizado unos mínimos que les permitiera a ellos producir y comercializar sus cosechas y todo eso, contar con carreteras, con medios de transporte, con centros de acopio que garantizaran todos esos procesos, pero que también los consumidores pudieran tener acceso a esos productos de manera mucho más segura, confiable, con buenos precios; que el agua y el aire que nosotros tomamos y respiramos pues fuera también bueno y que las relaciones entre nosotros no tuvieran que ser de competencia sino al contrario, relaciones de complementariedad, de solidaridad, que pudiéramos tener los espacios para el ocio, donde después de un gran trabajo semanal, pudiéramos descansar, encontrarnos y recrearnos, [entre otros aspectos no menos importantes] [...].
} 
[La idea sería configurar] una empresa que diga, estamos produciendo menos porque nos interesa vivir más, estamos produciendo menos porque nos interesa cuidar la reserva acuífera, estamos respetando la pluralidad sociocultural en la región, o estamos haciendo un análisis general de los tejidos culturales [...]. Uno entiende que el empresario invierte es para acumular, el problema es que esta atentado contra todos, y así lo que no se va a poder prolongar es la vida, aquí lo que hay es una especie de apuesta por romper con esas ideas ontológicas de desarrollo del sector empresarial, apelando a otro tipo de imágenes, de conceptos, de metas inclusive, [en donde] lo que está en el centro del debate es la vida."

\section{(In)Conclusiones}

La empresa y su lógica capitalista, con otras instituciones del sistema, viene conceptualizando e instaurando un desarrollo modernizador funcional al capital y a sus intereses en detrimento de otros ámbitos y realidades de las sociedades. Luego entonces, es necesario re-configurar lo empresarial en función de nuestra era y contextos. El reto es complejo, empero, una contribución significativa resultaría de re-diseñar la estrategia organizacional, por cuanto ello transformaría la empresa y sus impactos toda vez que la estrategia es variable clave en la coordinación empresarial. Claro está, el re-diseño estratégico deberá tener como horizonte hacer consonante a la empresa con el contra-desarrollo vital y la vida digna, plural y ampliada. Pensando en lo anterior, se propone la idea de la emergencia transicional de horizontes estratégicos posdesarrollistas que remite al acto de re-pensar la estrategia organizacional desde las reflexiones del posdesarrollo, las realidades sociales concretas y complejas y las propuestas de transición civilizatoria de múltiples movimientos sociales. En consecuencia, tal es una idea que resalta la necesidad de develar y apreciar lo oculto del mundo organizacional que cuenta con amplio potencial para re-significar los discursos y las prácticas estratégicas en favor de la vida. ${ }^{[14]}$

Ahora bien, ante el reto de la emergencia transicional de horizontes estratégicos posdesarrollistas, desde los discursos y prácticas organizacionales en Popayán - Cauca, se presentan como opciones disponibles tanto algunas apuestas del sector empresarial (aún ancladas a la lógica del capital) como los agenciamientos de las organizaciones sociales con potencial posdesarrollista que, al girar prominentemente en favor de lo social y lo ambiental, podrían permitir en mayor medida innovaciones estratégicas/empresariales significativas en favor del contra-desarrollo vital.

En efecto, a través de estrategias como la política de acción colectiva o asociatividad, política del lenguaje, movilización o movigestión, desarrollo de economías propias, tradición oral, interiorización o formación de conciencia, determinación de momentos clave, afectividad, formación en diferentes niveles, articulación, concientización / construcción, incidencia, realización de talleres, transición / inspiración o políticas del sujeto, las organizaciones sociales podrían hacer una importante contribución a la emergencia transicional de horizontes estratégicos posdesarrollistas. Por supuesto, no se ha de olvidar que las organizaciones en mención son heterogéneas y tienen conflictos y contrariedades, por tanto no son el lugar de la total pureza, lo higiénico, lo moral y lo positivo.

Es de resaltar que, a pesar de su relevancia, las praxis discursivas estratégicas de las organizaciones sociales referidas, resultan invisibilizadas y/o excluidas por los marcos categoriales que las presentan como lo otro capitalista o lo externo / excluido a la modernidad que para poder trascender su estadio de carencia, inmadurez e impertinencia deben trasegar por el tortuoso pero justificado camino hacia la lógica moderna del capital. Con estos actos de violencia epistemológica se niega el gran potencial revitalizador que subyace desde estas propuestas. Sin embargo, dada la pertinencia de estos agenciamientos ante las graves crisis socio-naturales que vivencia la humanidad y que demandan una re-significación de todas las esferas de la vida, se debe reconocer la importancia de ensanchar en esta dirección los campos del conocimiento.

Finalmente, se destaca que con la idea de la emergencia transicional de horizontes estratégicos posdesarrollistas, no se pretende negar lo empresarial ni configurar una empresa que se olvide de lo económico. El intento es el de promover un tipo de empresa que piense en lo económico pero como una esfera 
más para la promoción de una vida digna, plural y ampliada, lo cual requiere girar en diversas dimensiones y direcciones. Se trata entonces de conllevar a la empresa a ser una institución más compleja y relacional, reto trascendental en el marco de las transiciones civilizatorias y que ya está siendo concretado por algunas organizaciones.

\section{Referencias}

Ahumada, C. (1996). El modelo neoliberal: y su impacto en la sociedad colombiana. Bogotá: Ancora editores.

Alcaldía de Popayán (2012). Información general del municipio de Popayán. Recuperado el 15 de octubre de 2013, en http://www.popayan-cauca.gov.co/informacion_general.shtml

Arévalo, J. (2013). Relaciones e incidencias del pensamiento empresarial en el presente/futuro de las regiones. Revista UIS Humanidades, 41(2), 105-122.

Arévalo, J. (2014). Hacia el reconocimiento de una estrategia organizacional posoccidental para contextos interculturales poscoloniales: una crítica a la escuela del posicionamiento en el campo de la estrategia. Universidad \& Empresa, 16(27), 311-313. doi: dx.doi.org/10.12804/rev.univ.empresa.27.2014.11.

Arévalo, J. (2017). Repensando lo empresarial en defensa de un desarrollo para la vida: entronques e implicaciones del posdesarrollo sobre la estrategia organizacional. Investigación \& Desarrollo, 25(2), 172-198. doi: http://dx.doi. org/10.14482/indes.25.2.10964

Becerra, L., \& Puentes, Y. (2017). Análisis de las crisis de la dimensión social y las posibles soluciones vinculadas al postdesarrollo que han sido impulsadas por las empresas transnacionales en el contexto de la ciudad de Popayán entre los años 2010- 2015. Tesis de pregrado. Popayán: Universidad del Cauca.

Boucher, C. (1999).A description of Modernism and Postmodernism in the Context of Organisation Studies and Thinking about Management, RMIT Business Working Paper Series No. WP 99/8.

Braudel, F. (1997). La dinámica del capitalismo. Bogotá: Fondo de Cultura Económica.

Camisón, C., \& Dalmau, J. (2009). Introducción a los negocios y su gestión. Madrid: Pearson.

Carvajal, A. (2009). Desarrollo y post desarrollo: modelos y alternativas. Cali: Editorial de la Universidad del Valle.

Castrillón, D. (2007). Muros de bronce: Popayán y sus estancias históricas, humanasy territoriales. Cali: Impresora Feriva.

Crist, R. (1950). La personalidad de Popayán. Popayán: Editorial de la Universidad del Cauca.

Cúneo, M., \& Gascó, E. (2013). Crónicas del estallido. Viaje a los movimientos sociales que cambiaron a América Latina. Barcelona: Icaria editorial S.A.

De Roux, G. (1991). Procesos, politicas y coyunturas regionales y sus efectos sobre el campesinado nortecaucano. Cali: Universidad del Valle.

Duarte, C. (coord.) (2013). Análisis de la posesión territorial y situaciones de tensión interétnica e intercultural en el departamento del Cauca. Convenio PUJ e Incoder. Cali: Pontificia Universidad Javeriana.

Dussel, E. (1996). Filosofía de la liberación (Cuarta). Bogotá: Editorial Nueva América.

Dussel, E. (2014). 16 tesis de economía politica. Interpretación filosófica. México DF: Siglo XXI editores.

Dussel, E. (2015). Filosofías del sur: descolonización y transmodernidad. México DF: Ediciones Akal México.

Escobar, A. (2002). Globalización, modernidad y desarrollo. En C. Región (ed.), Planeación, Participación y Desarrollo (pp. 9-32). Medellín: Corporación Región.

Escobar, A. (2005). El "post desarrollo" como concepto y práctica socia. In Políticas de economía, ambiente y sociedad en tiempos de globalización. Caracas: Universidad Central de Venezuela.

Escobar, A. (2016). Autonomía y diseño: La realización de lo comunal. Popayán: Editorial Universidad del Cauca.

Escobar, A. (2017). Designs for the pluriverse: Radical interdependence, Autonomy, and making of the worlds. Durham, North Carolina: Duke University Press

EZLN, E. Z. de L. N. (2015). El pensamiento crítico frente a la hidra capitalista I. San Cristóbal Las Casas, México: EZLN. 
Furrer, O., Thomas, H., \& Goussevskaia, A. (2008). The structure and evolution of the strategic management field: A content analysis of 26 years of strategic management research. International Journal of Management Reviews, 10(1), 1-23. doi: https://doi.org/10.1111/j.1468-2370.2005.00108.x

Gibson-Graham,J. K. (2011). Una política poscapitalista. Medellín: Editorial Siglo del Hombre - Pontificia Universidad Javeriana.

Grosso, J. (2012). Del socioanálisis a la semiopraxis de la gestión social del conocimiento: contranarrativas en la telaraña global. Popayán: Editorial Universidad del Cauca.

Gudynas, E. (2011). Debates sobre el desarrollo y sus alternativas en América Latina: una breve guía heterodoxa. En Grupopermanente de trabajo sobre alternativas al desarrollo, Más allá del desarrollo (pp. 21-53). Quito: Abya Yala.

Guerras-Martín, L., Madhok, A., \& Montoro-Sánchez, A. (2014). The evolution of strategic management research: Recent trends and current directions. Business Research Quarterly, 17, 69-76. doi:10.1016/j.brq.2014.03.001

Handy, C. (1996). Beyond Certainty. Cambridge: Harvard University Press.

Hernández, S., \& Díaz, Z. (2003). Visiones alternativas del patrimonio local: Popayán una ciudad en construcción. Popayán: Fundación La Morada.

Johansen, O. (1992). Anatomía de la empresa: una teoria general de las organizaciones sociales. México DF: Grupo Noriega editores.

Latouche, S. (2003). Decrecimiento y posdesarrollo: el pensamiento creativo contra la economía del absurdo. Madrid: Ediciones de Intervención Cultural/El Viejo Topo.

Lee, N., \& Hassard, J. (1999). Organization Unbound: Actor-Network theory. Research strategy and institutional flexibility. Organization, 6(3), 391-404.

Macuacé, R., \& Cortés, R. (2013). Sobre migración y rururbanidad: Adaptación y transformación de la ciudad de Popayán a comienzos del siglo XXI. Territorios, 29, 117-142.

Maturana, H., \& Varela, F. (1987). The tree of knowledge: the biological root of human understanding. Berkeley: Shambhala.

Mera, Y. K. (2015). Inventario de organizaciones sociales y solidarias en el departamento del Cauca, 1era ed. [CD ROM]. Popayán, Cauca: Centro de investigación, promoción e innovación social para el desarrollo regional de la caficultura caucana.

Mintzberg, H. (1998). Safari a la estrategia: una visita guiada por la jungla del Management estratégico, $1 \mathrm{ra}$ ed. Buenos Aires: Ediciones Granica.

Mintzberg, H. (2001). Diseño de organizaciones eficientes. Buenos Aires: Editorial el Ateneo.

Moncayo, V. (2012). ¿Cómo aproximarnos al Estado en América Latina? En M. Thwaites (ed.), El estado en América Latina: continuidades y rupturas (pp. 19-49). Santiago de Chile: Editorial ARCIS.

Morrison, E., \& Milliken, F. (2000). Organizational silence: A barrier to change and development in a pluralistic world. Academy of Management Review, 25(4), 706-725. doi: 10.4236/ojbm.2018.62018 478.

Pabón, F., \& Rogríguez, D. (2018). La empresa transnacional en Popayán: entre las crisis de la dimensión económica y los horizontes postdesarrollistas. Tesis de pregrado. Universidad del Cauca. Popayán, Cauca.

Pérez, M. T. (2014). Barrio y vida urbana en Popayán 1920-1983. Popayán: Universidad del Cauca.

Quijano, O. (2012). Ecosimias: visiones y prácticas de diferencia económico/cultural en contexto de multiplicidad. Popayán: Editorial Universidad del Cauca.

Quijano, O. (2015). Sentipensar con la tierra. Nuevas lecturas sobre desarrollo, territorio y diferencia. Revista Nómadas, $42,264-267$.

Quijano, O., Corredor, C., \& Tobar, B. (2014). Desde el sur: desafiando y repensando las representaciones del desarrollo. Revista Nómadas, 40, 220-237.

Rifkin, J. (1998). El fin del trabajo. Barcelona: Paido\#s.

Ronda-Pupo, G., \& Guerras-Martín. L. A. (2012). Dynamics of the evolution of the strategy concept 1962-2008: A co-word analysis. Strategic Management Journal, 33(2), 162-188. https://doi.org/10.1002/smj.948. 
Sachs, W. (1996). Diccionario del desarrollo: una guia del conocimiento como poder. Londres: Zed Books Ltd.

Sánchez, O. (1967). Antología genial de los patojos. Popayán: Editorial del Departamento del Cauca.

Sisto, V. (s.f.). Teoría(s) Organizacional(es) Postmoderna(s) y la Gest(ac)ión del Sujeto Postmoderno. Barcelona: Universitat Autonoma de Barcelona.

Zuluaga, J. A. (2007). La levedad de la memoria símbolos e imaginarios ambientales urbanos en Popayán. Bogotá: Ediciones Axis Mundis.

Anexo 1

Casos de organizaciones sociales en el departamento del Cauca

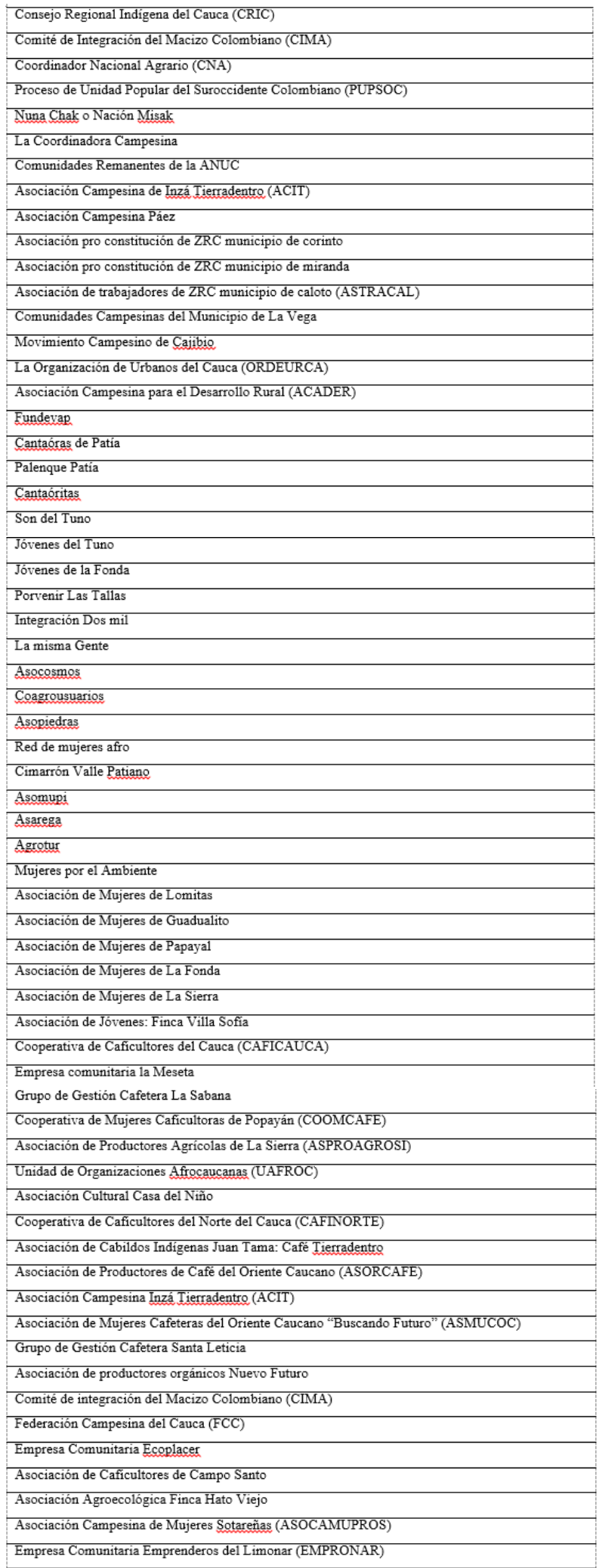

Fuente: Duarte (2013) y Mera (2015). 


\section{Notas}

[1] Entiéndase el concepto de contra-desarrollo vital como una alternativa al desarrollo en la cual la configuración de los estadios presentes/futuros de las sociedades, estará, por una parte, en coherencia con una expansión colectiva que priorice toda forma de vida y posea un carácter dilatado o extensivo en donde la pluralidad social y de la diversidad ambiental son centrales, y por tanto se consideraría pertinente construir a partir de las acciones de contradesarrollo de las comunidades (es decir agenciamientos, resistencias, negociaciones, subversiones y reelaboraciones de la gente o de los usuarios de prácticas con respecto a los proyectos de desarrollo) que se apropian del desarrollo para reorientarlo hacia otra racionalidad, edificando una modernidad alternativa, es decir, una racionalidad del mundo distinta a la eurocéntrica en donde se resignifican diversos conceptos como el de naturaleza y conservación, además comporta el universo diverso que quieren mantener las comunidades (Escobar, 2002). Por otra parte, a la luz del contra-desarrollo vital, la configuración de los estadios presentes/futuros de las sociedades estará en oposición a todos los efectos nocivos que han sido generados mediante los discursos, instituciones y prácticas del desarrollo hegemónico en las múltiples sociedades del planeta, que para ser superados hay que dislocarlos y proponer alternativas, no obstante, no se pretende generar un desconocimiento de los elementos benéficos que hubiese podido generar el desarrollo.

[2] Por criterios de alcance, en la investigación se enfatizó en las propuestas empresariales y principalmente en las de las organizaciones sociales. No se consideraron por tanto las apuestas de las organizaciones estatales.

[3] Para una discusión más extensa relacionada con el tema de este apartado, ver Arévalo (2017).

[4] El tema de la estrategia empresarial ha sido abordado desde diversos autores y corrientes teóricas. No obstante, en una revisión de campo del Management Estratégico, Mintzberg (1998) postula que la estrategia ha sido analizada principalmente por diez escuelas clasificadas en tres grupos: escuelas prescriptivas (diseño, planificación y posicionamiento) que analizan el cómo debiera formularse la estrategia, escuelas descriptivas (empresarial, cognitiva, política, cultural, ambiental y aprendizaje) que analizan de hecho cómo se formula la estrategia, y la escuela de la configuración con un enfoque holístico y unificador. En esta misma dirección, Guerras-Martín, Madhok, \& MontoroSánchez (2014), Nag et al. (2007), Ronda-Pupo y Guerras-Martín (2012) y Furrer, Thomas, \& Goussevskaia (2008), en revisiones sistemáticas actuales del ámbito de la estrategía y reconstruyendo históricamente el tema, concluyen que en síntesis, los temas centrales/actuales de trabajo en este campo son, la estrategia y su entorno, procesos estratégicos y alta gerencia, estrategia corporativa y modelos financieros, crecimiento y entrada a mercados, industria y competencia y perspectiva de la firma basada en recursos.

[5] Arévalo (2014) plantea que las escuelas o corrientes teóricas de la estrategia, tal como la escuela del posicionamiento, generan un conocimiento gestionado/aplicado según las características e intereses del sistema histórico capitalista y proponen analíticas sobre la estrategia de los monopolios del capital.

[6] Por supuesto, no se trata de negar (se pueden incluir) pero sí de sobrepasar los límites de las organizaciones modernas de nuestra sociedad.

[7] Por supuesto, para que un cambio de tal magnitud en la institución empresarial sea posible tanto teórica como empíricamente, se tendrían hacer ejercicios similares en torno a todos los demás discursos/prácticas relacionados con esta institución social.

[8] El suelo de expansión hace referencia a las áreas con muy buenas condiciones para la urbanización en el periodo de vigencia del Plan de Ordenamiento Territorial (POT).

[9] La liberación de esclavos amplió las formas de economía campesina de autoconsumo con opciones de autonomía desde productos como el cacao y el café, empezando una demanda de nuevas tierras para el trabajo.

[10] Según Maturana y Varela (1987), el organismo social se auto-produce autónoma y constantemente mediante un sistema de procesos complejos y concatenados. Es a partir de la acción efectiva que se logra tal auto-organización, con la cual a su vez, se responde a un entorno que impulsa cambios (no determina cambios, estos ocurren solo desde el sistema autopoiético). Así, la estructura autónoma se acopla progresivamente.

[11] Para entender la lógica y el proceso del círculo virtuoso/vicioso de la acumulación incesante de capital, podría revisarse la primera parte (es decir las primeras once tesis) del texto 16 tesis de economía política: interpretación filosófica de Dussel (2014).

[12] Sobre el tema de la relacionalidad se podrían revisar algunas obras de autores importantes tales como Mario Blaser, Marisol de la Cadena y Arturo Escobar.

[13] Es importante distinguir lo distinto de lo diferente. De acuerdo con Dussel (1996), cada individuo es distinto y no meramente diferente. La especie humana no está formada por una cantidad unívoca de individuos diferidos por su identidad (la diferencia), sino por individuos realmente distintos que tienen historias-biografías particulares (por tanto no es que existan diferentes culturas/identidades dentro de un mundo, sino de distintos mundos con distintas historias). Entiéndase que lo diferente, aunque difiere, hace parte de lo mismo, de una totalidad (aunque tenemos diferentes "yo", todos somos humanos); por su parte lo distinto refiere a algo que es una totalidad otra, un otro desde siempre (tiene 
otra historia), es la innovación, tiempo nuevo, que puede hacer una revelación novedosa que fecunda la tradición y la hace historia.

[14] Por supuesto, no se trata de negar (se pueden incluir) pero si de sobrepasar los límites de las organizaciones modernas de nuestra sociedad.

* Artículo de investigación científica.

\section{Licencia Creative Commons CC BY 4.0}

Cómo citar: Arévalo V., J. M., Mosquera P., F., \& Cáceres B., D. (2019). Develar y apreciar la diversidad organizacional: discursos y prácticas para re-imaginar la empresa y la estrategia en función de la vida. Cuadernos de Administración, 32(58). https://doi.org/10.11144/Javeriana.cao32-58.dado 